\title{
Which Communicative Strategies Do Slovak Pediatricians Choose to Facilitate Parental Decision-Making about Childhood Vaccination?
}

\author{
Jana Bašnáková, Mária Hatoková \\ Institute of Experimental Psychology \\ Center of Social and Psychological Sciences, Slovak Academy of Sciences
}

\begin{abstract}
One of the most common factors underlying delaying or refusing childhood vaccination are concerns about vaccine safety. Parents often struggle with conflicting information about their adverse effects, vaccine-preventable diseases, and also with emotions such as fear or distress. Pediatricians are in a privileged position to facilitate parental decision-making related to vaccination, but can also tip hesitant parents towards vaccine refusal, especially if they do not communicate effectively. This qualitative study explores the decision-making processes of Slovak pediatricians in choosing communication strategies facilitating parental decisions about vaccination. We conducted literature search to identify recommendations about effective and ineffective communication strategies related to childhood vaccination, as well as in-depth interviews with 15 pediatricians. The results show that pediatricians typically lack formal training in communication with parents, but use a large number of effective communicative strategies that they have acquired during their clinical experience. However, often these decisions are not being made explicitly, and some pediatricians struggle with specific situations and types of parents. We conclude that implementing formal communication training in relation to childhood vaccination would make pediatricians' daily work more efficient and less emotionally taxing.
\end{abstract}

Key words: vaccination, decision-making, communication strategies, vaccine-hesitant parents

\section{Introduction}

Vaccination has long been considered one of the cornerstones of children's health (Brunson, 2013). However, immunization rates in Slovakia have been steadily declining over the past years for all mandatory childhood vaccines; in fact, for the MMR vaccine, they have declined be-

This research was supported by grant APVV-036112 - 'Decision Making of Professionals: Process, Personality and Social Aspects'.

Correspondence concerning this paper should be addressed to Jana Bašnáková, Institute of Experimental Psychology, Center of Social and Psychological Sciences SAS, Dúbravská cesta 9, 84104 Bratislava, Slovak Republic. Email: jana.basnakova@savba.sk

Received November 16, 2016 low the critical level of $95 \%$ necessary for maintaining herd immunity. For pediatricians and epidemiologists, one of the recommended solutions has been to educate parents about the significance of vaccination (IPH, 2015). The aim of this qualitative study is to identify how Slovak pediatricians make decisions regarding communicative strategies for parents about childhood vaccination, and which strategies they choose to use.

One of the most common factors underlying delaying or refusing childhood vaccination are concerns about vaccine safety (Gust, Darling, Kennedy, \& Schwartz, 2008; Smith, Chu, \& Barker, 2004). Even parents who fully vaccinate their children report feeling worried about their possible side-effects and impact on the child's immune system (Kennedy, Basket, \& Sheedy, 2011). For parents, making decisions about vac- 
cination of their child can be a cognitively and emotionally demanding process (Casiday, 2005; Connolly \& Reb, 2012). Often, they are susceptible to various cognitive shortcuts, such as overestimating the vaccine's adverse effects by relying on readily accessible information from vivid anecdotes, and not on more balanced statistical information. However, parents, even those who hesitate with vaccination because they consider vaccines unsafe, can be positively influenced by pediatricians (Smith, Kennedy, Wooten, Gust, \& Pickering, 2006). Therefore, one way pediatricians could facilitate parental informed decision making would be learning to choose effective risk-communication strategies.

Decision-making is a process of selecting or choosing among several alternatives, in order to "...maximize utility or expected utility" (Edwards, 1954). According to Hastie (2001, p.656), it has three main components: a) what action to take (what are one's options and alternatives); b) beliefs about objective states, processes, and events in the world (including what is the desired outcome and means to achieve it); and c) desires, values, or utilities describing the consequences, which are associated with the outcomes of each combination of actions and events. Based on this classification, the pediatricians' decision-making process about vaccine-related communication with parents may involve: a) considering their options regarding the possible outcome - e.g. whether to fully and timely vaccinate, or whether to space out, delay, or not administer vaccines to this particular patient at all. This decision involves assessing the patient's actual health, his/her genetic predispositions and environment, etc.; b) their beliefs about risks inherent in vaccinating vs. not vaccinating, with regard to achieving optimal health of the patient; and c) their desired consequence is achieving/maintaining a healthy child, as well as preventing VPDs and their spread among the population.
With regard to the values mentioned in c), we presume that most pediatricians assume that vaccination is important and adhere to the recommendations of the main authority on public health, the Institute of Public Health (IPH, 2015); and, in line with that, they try to communicate that vaccination is important. However, "effective communication" does not mean coaxing or manipulating vaccine-hesitant parents into vaccinating their child. Rather, it means removing barriers to decision-making by helping them to make informed analysis based on available evidence, and not on insufficient or erroneous information, fear or misrepresented risks.

All our respondents expressed a positive attitude to vaccination, and even in cases when they did not admit it openly, their implicit intention was to persuade parents to have their children immunized. One of the main reasons for this was the perceived necessity to maintain herd immunity. This attitude permeated pediatricians' implicit or explicit communication strategies, and it is also adopted in this article.

\section{Pediatricians and Effective Communication with Parents}

There is currently a large number of interventions aimed at increasing vaccine acceptance among parents, but only a handful of them directly targets pediatricians' communication strategies (even though some studies use the term "communication strategies" to describe global information strategies, such as leaflets or public campaigns). However, the efficiency of general interventions seems to be limited (Sadaf, Richards, Glanz, Salmon, \& Omer, 2013).

Recently, the focus has shifted towards exploring particular communication strategies, even though this work is still in its infancy (Kaufman et al., 2013). The logic of this shift is that effective interaction can address concerns about vaccines and increase parents' motivation; on the other hand, poor communication 
from a pediatrician can "tip" a hesitant parent towards refusal or fail to motivate a cautious parent towards acceptance (Leask et al., 2012). Effective communication, however, does not simply entail presenting information or trying to persuade parents "at any cost". Such approach could backfire, especially with parents who are already in doubt. Effective communication is a complex process, embedded within wider social context: e.g., the doctor-patient (or parent) relationship of trust, parents' experience, beliefs, personality, information-processing strategies, etc.

Currently, there are two trends in the literature. One is devising integrative communication approaches for the pediatrician to adopt and use as a whole, such as the C.A.S.E. system (Jacobson, Van Etta, \& Bahta, 2013). To date, however, there is no direct empirical evidence that such an integrated approach is effective. The other trend is testing different separate strategies, with the ultimate goal of providing ingredients for successful communication between pediatricians and parents (e.g., Leask et al., 2012). In the following section, we will review the available communicative strategies presented in the literature.

\section{Effective Communication Strategies}

a) Building and maintaining a trusting relationship between pediatricians and parents

Several studies have shown that a trusting relationship between parents and their healthcare provider is the single most important aspect of effective vaccine risk communication (Smith, 2015). For example, a survey among 7695 parents concluded that health-care providers have a positive influence on parents' decisions to vaccinate, including those who believe that vaccines are unsafe - if there is honest and respectful relationship between doctors and parents. This is especially important for parents who express concerns about vaccine safety or have misconceptions about the benefits and risks of vaccination (Smith, Kennedy, Wooten, Gust, \& Pickering, 2006).

A trusting relationship is one of openness and cooperation. Benin, Wisler-Scher, Colson, Shapiro, and Holmboe (2006) list a number of characteristic behaviors of a trusted pediatrician: e.g., s/he spends enough time with the parent and child, listens to their concerns and tries to accept and address them (instead of dismissing them as "petty" or "uninformed"); $\mathrm{s} /$ he also treats parents and their children as individuals. There are many other behaviors that a trusted pediatrician does and does not engage in, such as appropriate body language, comprehensive and fair use of information, or actively eliciting parental concerns about vaccines so that these can be dealt with (Leask et al., 2012).

b) Tailoring communicative messages for different types of parents

Not all parents are the same, and a universal, one-size-fits-all approach is unlikely to be effective. Leask et al. (2012) integrated studies on parental behavior during vaccination-related decision making and identified 5 types of parental attitudes towards vaccination: those who accept mandatory childhood vaccination without any questions or hesitations (unquestioning acceptor), those who accept but express some concerns (cautious acceptor), those who hesitate with the decision (hesitant) or decide to delay/adjust vaccination schedule (late or selective vaccinator) and finally those who refuse vaccination completely. The authors suggest different strategies for talking to these types of parents, including presenting information in different formats (e.g., anecdotes vs. statistical arguments) and going into varying depths of evidence.

There are undoubtedly other differences between parents - as Williams (2014) notes, decision-making process of hesitant parents is likely complex and some of its aspects are difficult to 
measure. It is therefore important for the pediatrician to remain flexible in her/his approach and attempt to recognize what communication style is best suited for which parent.

c) Optimal timing of conversation about vaccination

Timing is potentially important because once parents have made their decision, they might not be open to any new information that would motivate them to reconsider it. In fact, such attempts might lead to belief-entrenchment (Nyhan, Reifler, Richey, \& Freed, 2014) or backfire effect (Tourangeau \& Rasinski, 1988). Brunson (2015) identified three circumstances when parents were particularly open to messages about vaccination. The first opportunity arose when they first started thinking about vaccinating their first child, although the exact timeframe differed among families. Some started after the child was born, while others even before they were planning a child. The second opportunity arose when they were still in the process. Some parents felt they did not have crucial information about, e.g. an optional vaccine or certain additives, and were waiting to receive new information or relevant arguments. Lastly, even a "final" decision was still amenable to change if their circumstances have changed, for example when their children became ill and parents started perceiving them as more vulnerable, or when they experienced real or perceived bad reactions to vaccines. Likewise, when the vaccination schedule changed, this change led some parents to reconsider their choices in terms of choosing fewer vaccines or delaying their application. On the other hand, some parents changed from refusing vaccines to a complete, on-time vaccination because they re-assessed the inherent risks due to travel, disease outbreak in their vicinity, start of schooling and so on. Therefore, pediatricians' effective communication should take into consideration parental stage of decision-making. d) Message framing and vaccination pursuit

So far, there have only been a handful of attempts to implement changes in the particulars of communication style between parents and health-care providers about vaccination. The results are mixed, suggesting that it matters what and how is communicated (Henrikson et al., 2015). As this kind of research is still in its early stages, these methods have not been tested for effectiveness (Williams, 2014).

Opel et al. (2013) videotaped 111 parent-doctor interactions and showed that the style of opening communication about vaccination during a visit to the pediatrician made a significant difference for parents' decisions. "Presumptive" style of communication ("Well, we have to do some shots.") was associated with a higher acceptance rate than "participatory" style ("What do you want to do about shots?"), which also seemed to invite more voiced hesitance. When the outcome was measured as "parental verbal resistance", communication style was highly predictive of whether parents simply accepted vaccination or voiced any concerns or hesitation. However, when the outcome was measured as acceptance of all vaccines at the end of the visit, the effect size of the difference between communication styles was very small, albeit still significant (Opel et al., 2015). Interestingly, participatory style was associated with a more positive rating of parents' visit experience, with a much larger effect size. Therefore, one might question whether a presumptive style is always better than a participatory style.

The latter seems to invite parents to voice their concerns, which a trained pediatrician can handle to mutual satisfaction. This seems especially desirable with parents who are not fully convinced and need their doctor's reassurance. In addition, a high visit experience might translate into more trust towards the healthcare provider and therefore more efficient decision-making in the long run. One clear take-home mes- 
sage from this series of studies is that (respectful) pursuit is an important factor in parental decisions.

\section{e) Working with emotions}

Most authors agree that providing information to hesitant parents is not enough. It is equally important to address the emotions behind vaccination-related decision making, especially parental fear. One integrative approach taking emotions into account is known under the acronym C.A.S.E., which summarizes a list of 4 steps to follow during a discussion between a parent and a health-care provider (Jacobson et al., 2013). The pediatrician should first "Corroborate", i.e. set the tone for respectful talk, in which s/he acknowledges the parent's concerns and tries to find a point of departure on which they can both agree. Next, the "About me" step encourages the pediatrician to show her/himself as actively involved in the process of critically evaluating available evidence about vaccines, especially their safety. The pediatrician should state how s/he had built his/her knowledge base and expertise, e.g. that $\mathrm{s} /$ he is regularly updated about information on adverse effects of vaccines. Only the third step, "Science", brings in the relevant scientific information about vaccine safety. Lastly, "Explain" concerns explaining the physician's advice to the parent, based on science (see Table 1 for an example).

The pediatrician has to make sure that her/ his answers are tailored to the specific situation (e.g., choose simpler/more complex language based on educational level of the parent) and they have to be sincere (not to say things that are not true), as the crucial prerequisite for a successful parent-doctor dialogue is trust.

Pediatrician's emotions, e.g. frustration with vaccine-refusing parents, are also entering into the process, although there is no particular information in the literature on how to handle them, apart from gaining insight into these emotions evoked by the situation (Lyren \& Leonard, 2006).

f) Risk-benefit communication and presenting information beforehand

Lastly, there are two aspects of communication that deal with the format of presenting information about vaccines and vaccine-preventable diseases (VPDs). Again, there is some general research on these issues but not much in relation to communicative strategies of pediatricians. Leask et al. (2012) mention that it is good practice to give parents accessible information beforehand, so that they can come to the discussion with targeted questions, or at

Table 1 Example of the CASE approach, adapted from Jacobson et al., 2013

\begin{tabular}{ll}
\hline CASE step & Pediatrician/Parent dialogue \\
\hline Corroborate & "What is your specific concern?" (waiting for answer, e.g. too many \\
& vaccines too soon) "That's a valid concern. The current vaccination \\
& schedule is indeed larger than in the past." \\
& "I get regular updates on vaccine composition and changes to \\
& vaccination schedule and I am confident that modern vaccines are \\
different from the ones your generation received." & "Technology is much more advanced now and although children get \\
& more shots, they in fact receive fewer immune-reactive antigens. In \\
Science & addition, even a five-aspect vaccine is less of a challenge for your \\
& baby's immune system compared to what s/he fights off every day." \\
& "If s/he were my child, I would be vaccinating her today". \\
\hline
\end{tabular}


least that there is some common ground between the doctor and the parents. Risk-benefit communication should be also very clear, as parents might be misled by vivid, but statistically rare examples of adverse reactions, and underestimate the complications of VPDs at the same time. Based on their review, Leask et al. (2012) recommend using visual aids and presenting statistics in easy-to-grasp format, e.g. percentages or words ("one in five patients").

\section{Vaccination Decisions in the Slovak Popula- tion}

While some aspects of vaccine hesitancy and refusal are definitely universal, it is reasonable to expect country- or culture-specific variations as well. For example, there might be differences in the perception of medical authority, as the shift from authoritative to shared decision making (Hertwig \& Hoffrage, 2013) might be in various stages of progress in various countries. There is currently very little data on how Slovak parents make decisions about vaccination. A notable exception is a qualitative study by Masaryk, Hatoková, and Túnyiová (2015), who lead focus groups with female students and mothers of small children and identified factors that hinder their decision-making process. The most relevant in this context are lack of trust in the health-care provider, perceived lack of adequate resources and balanced information, and inadequate environment to make relevant decisions during a well-child visit where vaccination or vaccination discussions take place.

Lack of trust in the health-care provider is generally caused by what parents view as nonoptimal decisions regarding their child's treatment, for example over-prescribing antibiotics for illnesses which they believe do not require antibiotic treatment, or incorrect diagnoses. Focus group participants also felt that the pediatricians were not being sincere about vaccines' adverse effects, as most doctors would only mention mild adverse effects such as fever, pain or redness, and avoid mentioning rare but serious ones. While this seems like a strategy not to scare parents, it also creates mistrust because adverse effects of vaccines are well-known and the information is publicly available. Lastly, participants with small children mentioned that it is very difficult to hold any sensible discussion during an actual pediatrician visit because of the overall atmosphere. The parent has to take care of a distressed child and listen and process medical information at the same time.

To sum up, the goal of the present study was to identify which communicative strategies do Slovak pediatricians implicitly or explicitly choose in order to facilitate parental decisions about vaccination.

\section{Method}

In order to study how pediatricians choose vaccination-related communication strategies, i.e. how they facilitate informed parental decision-making, we conducted in-depth interviews with 15 pediatricians recruited by a professional recruiting agency based on pre-determined criteria. These were: a) primary-care doctors, i.e. those who routinely vaccinate infants; b) based in the capital city (because it has the highest incidence of refusing parents); c) agree with recording the interview on an audio device; and d) having sufficient variability in age and length of primary care experience. We only had vaccine-accepting pediatricians in the sample because it was virtually impossible to reach pediatricians who openly encourage parental refusal (even though there is "unofficial" knowledge among parents who these pediatricians are). We are aware of some of the possible disadvantages of such decision and mention them in the Discussion. In the final sample, all of the pediatricians were women, reflecting a trend in Slovakia where the majority of pediatricians are 
female. Their average experience in pediatric practice was 17.3 years $(S D=13.8$, range 2 - 38). The interviews, conducted by Hatoková between December 2015 and March 2016 lasted about 60 minutes and doctors received financial compensation for their time.

Each interview was based on a script with several organizing topics. Two of them were background topics: how they perceive their role as a pediatrician, and their relationship with patients' parents, as well as how they perceive the (changing) public perception of pediatricians. The other three were focused on direct examples of doctor-parent communication (Characterize communication with today's parents. Under what circumstances is it not effective?), their vaccination experience (What comes to your mind when you hear the word "vaccination"? What are the most common parental arguments against it? What is your most effective pro-vaccination argument?), and the role of emotions in their practice (How does a pediatrician feel when parents challenge her advice? Do you take notice of parental emotions during your appointments?).

The qualitative analysis of interviews was done in Atlas.ti. We identified any information related to how pediatricians implicitly or explicitly decide about how to communicate with parents about vaccination, with special focus on topics/strategies highlighted in the Introduction. Since this study was a follow-up to focus groups with mothers about vaccination-related communication with their pediatricians (Masaryk, Hatoková, \& Túnyiová, 2015), we used codes from this study as guides in the current analysis. Each author coded all interviews separately and we then discussed any inconsistencies, until agreement was reached. As this was an exploratory qualitative study, we did not attempt to analyze any numeric information, e.g. which strategy was more frequent.

Below, we report all communication strategies that the pediatricians explicitly or implicitlymen- tioned in the interviews, organized by the main topics identified in the Introduction. When referring to differences between doctors with longer and shorter experience, the former group had $20+$ years of pediatric practice experience $(\mathrm{N}=7)$, whereas the latter had 10 and less $(\mathrm{N}=$ 8). Our motivation for this split was based on the premise that doctors with longer experience had the chance to personally witness some of the VPDs, whereas the rest did not, as they have been virtually eradicated by the time they started practicing pediatric medicine. Also, pediatricians with longer clinical experience have a larger "evidence base" for any more serious adverse effects caused by vaccination. The split is, however, only arbitrary as it is difficult to exactly pinpoint the time point by which there were almost no VPDs present in the Slovak infant population (e.g., measles or polio).

We published preliminary results based on these data, including 30 additional paper-andpencil questionnaires based on these scripts and distributed on a conference for pediatricians, in Bašnáková and Hatoková (2016). The analysis focused on perceived barriers to vaccination from the pediatricians' perspective.

\section{Results}

\section{Differentiating between Types of Parents and Tailoring Vaccination Messages Accordingly}

Many pediatricians in our sample did differentiate between types of parents based on their vaccination status and dedicated the most resources to vaccine-hesitant parents. Overall, pediatricians had only a very small number of refusers in their practice and most of those who had doubts about vaccination were vaccinehesitant parents (VHP).

Pediatricians reported two strategies for dealing with refusing parents. Some tended to „screen" all parents before accepting their children as patients. In case parents refused vacci- 
nation, doctors would not take these families into their care (unless they were legally obliged to, based on their place of residence). Others advised them to transfer to a different pediatrician once it had become clear that no amount of persuasion will change these parents' minds. However, there was a different trend in dealing with refusers among more and less experienced doctors. Doctors with less clinical experience tended to be more accepting towards parents who refused vaccination. They would try to get them to vaccinate but if met with refusal, they would wait and re-open the conversation periodically to check if parents' attitudes have not changed in the meantime.

Even though "exclusion" approaches are logical and clearly protect the rest of the children who are in doctors' care and could not have been vaccinated (yet), the literature suggests that adopting a waiting approach can be more efficient in the long run (e.g., Brunson, 2015). There are instances when even initially refusing parents change their minds and the pediatricians' biggest asset is to keep communication lines open and continue building mutual trust.

There was also a difference between more and less experienced doctors in their use of direct persuasion towards vaccine-hesitant parents. Doctors with longer experience would be more actively persuasive, whereas those with shorter experience would be more likely to just offer arguments, but leave the final decision to the parents. This can be, again, due to their different clinical experience, as the latter group have not generally witnessed VPDs and might have had the tendency to not consider them to be as dangerous as those doctors who witnessed tetanus, smallpox, mumps, etc., and their complications. Another possibility is that younger pediatricians are closer to their patients' parents in terms of age, which means they might more vividly remember making vaccination decisions for their own children, and might therefore find it easier to adopt the parents' perspective and understand their fear.

For example, one doctor with 29 years of pediatric practice experience (PPE) reported that: "And I am telling parents, that nothing smarter and better [than vaccination] has ever been invented in medicine, even though some of them think that it is bad [...] and I tell them that you haven 'texperienced it but I have, because I have been a pediatrician for a long time [...]. And I amtelling [them], I have seen a twenty-seven year old dying of tetanus, I have seen, thankfully only one, child with diphtheria. And right when I started, I think one child with pertussis. Sadly, I have had my own patient here with pertussis two or three years ago, fortunately after the first round of [pertussis] vaccine, which had saved his life, but I also have to say that getting the diagnosis was very difficult [...] . ...I just don't know how will young doctors diagnose it, who havenever seen pertussis in their lives, they have never seen diphtheria, or polio. Well I cannot imagine at all what they will do because they [the diseases] are starting to emerge again." (I9, 29 years ofPPE)

A pediatrician with short clinical experience said that ,, I think that vaccination works but I take it as certain invasion of the organism and it can really cause some damage in the organism... There are many types of vaccines, some of them are unnecessary, we really do not have to vaccinate against everything. Definitely not against hepatitis $B$, pneumococcal disease. Those should be, I think, voluntary. Even Hib could be essentially on a voluntary basis. "(I10, 4 years of PPE)

As far as communication style goes, we do not have direct evidence about how pediatricians tailored their communication to the parents' vaccination attitudes, e.g. what expressions they used. However, it seems that they generally tended to adjust to their education level or to how much information these parents already had from other sources. 
In addition, some doctors attempted to adjust their communication style to parental personality - e.g. when parents were anxious, they tried to be maximally reassuring. However, others said that they were unable to effectively communicate with parents with whom they "clash" personality-wise, or when parents were stressed out due to time pressure or a previous stressful Emergency room visit and were "angry at everybody" or when they were aggressive (I2, 35 PPE). Such encounters tended to be emotionally exhausting.

\section{Timing of Delivering Vaccination Informa- tion}

The question of timing was reflected by our respondents in three ways. First, several pediatricians said that they are aware that parents needed time to make up their minds and therefore start with vaccination information early, often during the mother's prenatal visit or about two months before the first shots are due.

"Essentially, I bring it up during the neonatal visit and they will meet me three more times until the [first] shots. So it is somehow gradually unpacking itself. Their opinion and my opinion. So there are no headlong emotions or contacts. "(I4, $38 \mathrm{PPE})$

Secondly, there were doctors who deliberately postponed first vaccines until the end of the third month, even though they were due on the previous well-child visit. This gave the parents some time to think about their decision, but it also postponed vaccination to a time when the baby was already relatively strong, families started feeling more comfortable with him/her and they were past the first overwhelming months. Some doctors reported that they avoided discussing the topic on the first wellchild visit because they wanted to make sure that the mother had time to adjust to her new reality. “...you know, here comes an expecting mom and she wants me to admit her baby to my practice, and I ask her what do you need to know from us? She asks me whether I will come for the first visit [to her household] because that is what she fears the most. Then she asks me, what about vaccination? And I tell her that we have loads of time for that. Because that's true, three months is loads of time because she has lots of other, more serious things, which have to happen and we have to work through them before vaccination... I will start talking vaccines only after the first month. " (I1, 10 PPE)

In a third, related strategy, some doctors chose to "ration" information in a way that parents had the chance to get used to the idea of vaccination and also had time to process the necessary information and resolve their worries, at least to some extent. These pediatricians made sure to hand out vaccination leaflets either on the very first well-child visit, or on the visit just before the first shots. We do not have detailed information about the type of leaflets parents received, although some mentioned that they try not to offer information from pharmaceutical companies. However, the leaflet listed on the main expert pro-vaccination website endorsed by official medical authorities ("http:// www.sprievodcaockovanim.sk," n.d.) is actually sponsored by a pharmaceutical company, which might be compromising, at least for some parents. Apart from that, the leaflet is detailed, with accessible language and exhaustive information, including common anti-vaccination myths.

Lastly, doctors, based on their experience, deliberately adopted a patient attitude about the first vaccination and did not "push too hard". Some explicitly mentioned that this was a mutual trust-building exercise, and that they were aware how fragile trust could be in the first months of the child's life. At the same time, pediatricians did not want to compromise the chance to vaccinate the child at a later timepoint, given that refusing parents might re-visit their decision and change their mind. 
„Because my attitude is that I prefer to vaccinate the child, even a year later [than planned] but s/he will be vaccinated. If I were radical, it is mandatory and that's that, and go away if you don't like it, then I would lose these parents for vaccination for good." (I11, $10 \mathrm{PPE})$.

Some pediatricians chose a strategy to build a trusting relationship by presenting the parents with all their possibilities and being maximally cooperative within these limits. In the following example, the pediatrician was motivated by the fact that she was acutely aware of parental fear.

"You know, I am trying to help because I see that they are terrified about it. Such parents get extra hours [...], they want to sit down and talk it through and we are looking for ways to make it easier for the parents because, ultimately, it is the parent's decision. [...] So we are trying to find something, if they want to postpone vaccination, even though I explain that preemies are immunized even earlier [...]. Or we agree to space out the vaccines [...]. We talk this through so that they know what our options are ... so we are really trying to find some kind of solution for these moms so that we manage to vaccinate the child on time. To comfort the mom, [to show her] that we do everything possible to make it less harsh, so that she is more relaxed [about it]. "(I2, $35 \mathrm{PPE})$.

\section{Addressing Emotions}

Pediatricians in our sample were aware that vaccination-related decision making leads to various emotions, most notably fear. The issue of emotions was reflected in the interviews in several ways: in dealing with parental emotions of fear, in using emotion-eliciting communication strategies, and in pediatricians dealing with their own emotions.

While all pediatricians were aware of parental fear, they chose different strategies to deal with it. Several of them said that special attention should be given to handling parental fear in general, not only regarding vaccination, because for some parents, fear is overwhelming. "...people are very afraid and they are afraid even if [the child] coughs just once, and they are afraid when [the child] has fever and they cannot do anything without first calling the doctor. And I am now talking about routine diseases." (I10, 4 PPE)

There were also voices claiming that this generation of parents is more afraid than previous generations, although opinions about why that is were mixed: from lack of medical education to just general chaos and fear, perhaps inherent in the fact that there is lots of conflicting medical information around and that makes parents uneasy.

Parental fear and anxiousness were also often cited as the reasons why parents delay vaccination and wait until the child is older. However, this may end up with the child receiving several vaccines within a short timeframe, each with its own adjuvants and stabilizers. Pediatricians saw their role in explaining VPDs' characteristics and consequences, and those with more clinical experience tried to balance parental fear of adverse effects by pointing out adverse outcomes of VPDs. Younger pediatricians also typically acknowledged that there were some adverse effects of vaccines and informed the parents what to do when their child encounters one, beyond the usual localized skin reaction. However, pediatricians from both groups said that before vaccination, they chose to wait for parental informed decision, to make sure that parents were truly comfortable with vaccination. Therefore, when they saw that the parent was very afraid, they decided to reschedule.

"Well, I never put pressure on them because if anything happens, they will blame me. But I know that as long as the mother identifies with the idea, because she has to feel like she herself wants it. If it is against her conscience, 
then I tell her that she rather shouldn't. Because she has to identify with it, that I am right and that she believes me." (I5, 2 PPE)

Lastly, one recurrent issue was the burden of managing one's own negative emotions, some of which had to do with their own fear and sense of responsibility in the rare but possible case of adverse effects or anaphylactic shock.

"[...], because of course, everybody is afraid, I am not saying that I am not afraid when I deliver vaccines, yes. For me, it would also be easier not to vaccinate, but from the perspective of the future, what is going to happen, one does not want to leave a mess after oneself. Of course I will listen to the parent and tell her what could happen and then I of course also tell her my [opinion] because one cannot just give up. To be right. And one has to have experience in order to do that, has to be interested and have some knowledge to be able to come up with the right answer. " (I7, $35 \mathrm{PPE})$

Other negative emotion-eliciting situations had to do with vaccine refusers or simply the fact that they were not able to persuade a parent to vaccinate, even though they considered it in the best interest of the child. Most of the pediatricians claimed that they were aware of these emotions and that they tried to not transfer them to the parent, unless the situation required going into an open confrontation. In dealing with vaccine-refusing parents, they would go through phases: from anger and outrage, through helplessness that they were not able to formulate their arguments in a more persuasive way, to acceptance of the situation. Often the result of such acceptance was that they just pragmatically presented balanced arguments to parents and left the final decision to them. Before reaching some kind of a "closure", or learning how to deal with their own negative emotions, this process often used to be emotionally draining. Two older pediatricians (29 and 35 PPE) seemed to channel such nega- tive feelings into somatic problems, since they perceived non-vaccination as their personal failure.

"(...) we do not have many unvaccinated [children], I have about three children. And I have, I have paid for it with high blood pressure, because I have perceived it as a personal failure." (I9, 29 PPE)

As this was very exhausting, those pediatricians for whom vaccine resistance amounted to a "paradigm shift", had to adjust by choosing new strategies - changing communication from more authoritative towards more participatory, using examples from their clinical experience and personal life or giving parents more time. Other new strategies for reaching consensus with parents were simply patiently reminding them about vaccination during well-child visits or making compromises - delaying or even spacing out certain vaccines.

\section{Message Framing and Vaccination Pursuit}

Our interviews did not yield detailed information about whether doctors used presumptive or participatory style of communication, or a combination of both. However, we directly asked about whether pediatricians opened the topic several times if met with initial refusal or hesitation. The majority of doctors did engage in some level of persuasion. In general, those with more clinical experience tended to persuade parents more actively, for example calling to reschedule missed appointments, or discussing options of spacing out vaccines.

"Well, again, we have to find the right argument, which will simply trump [the parent's] argument. There is no other way, you have to [persuade] as an expert, as a mother, as I don't know what. You were vaccinated as well. And simply put everything into it [persuasion], even some diseases, God forbid. Your kid wants to travel? S/He wants to. So here you go." (I4, 38PPE) 
Younger doctors would "push" a little less, presenting information and leaving the final decision to parents:

"Well, I am saying that it is not demanding for me personally because I am not trying to persuade them, so I do not find it demanding. Because I don't think that my goal is to persuade parents to vaccinate their children. So I do not consider it a burden and I do not need to fight it. "(I10, 4 PPE)

\section{Risk-Benefit Communication}

There is little detailed information in our data about how exactly doctors convey and balance risk-benefit information. In general, it seems that while parents concentrate on serious adverse effects of vaccines, doctors choose to do the opposite - concentrate on risk of VPDs. This is understandable, as doctors are familiar with potential dangers of these, sometimes eradicated, diseases, and some of them have even directly witnessed them in their practice. At the same time, they have personal clinical experience with few or no serious adverse effects of vaccines and this is the "basis" they are building their personal statistics on.

The tendency to avoid mentioning serious side effects of vaccines among pediatricians in general was also reflected in parents' reports from another study from our team (Masaryk, Hatoková, \& Túnyiová, 2015). When explicitly asked about this in our interviews, several pediatricians reported that they decided to adopt such strategy because these adverse effects are very rare, or because they do not want to stress or scare parents even more. One pediatrician (I15, 2 PPE) said that giving too much information can be overwhelming for parents and adverse effects mentioned in connection with vaccines include some rare ones which are simply due to the sheer number of vaccinated children. However, she also said that people should be somehow better informed about a practice that is being done so routinely.

One doctor admitted that not informing about any serious adverse effects is a potentially risky practice, as parents know of these side effects and perceive the doctor's silence as evidence that she wants to hide this information, which leads to perceived lack of trust. A doctor relatively new to pediatric practice (5 PPE) said that adverse-effects reporting can be used as a trustbuilding strategy:

"What worked for me was that you have to tell them adverse effects, and the more adverse effects you mention, the more they trust you. If you just tell them that [children] will have a red mark on the skin where the needle went in... No! Because they have read [about adverse effects in] the literature. "(I14, $5 \mathrm{PPE})$

As for presenting the balance of risks and benefits, we do not have any evidence that pediatricians would explicitly illustrate risk and benefits with, e.g. visual aids or statistics. However, they did report a number of arguments with which they attempt to remind parents that VPDs were still real. Several of them mentioned examples of international travel, refugees bringing new diseases, or recent outbreaks in certain parts of Slovakia or Europe due to locally low levels of immunization.

\section{Building Trust}

All pediatricians stressed the importance of trust in their relationship with parents. Mutual trust, or lack of it, affects all medical and parental decisions, not only those related to vaccination.

"[...most important aspect of the parent-doctor relationship?] Probably the parent's trust in the pediatrician. That she will comply with [the doctor's] decision, because she will let the pressure off herself and at the same time will give us a free hand; because as soon as it is the other way around, that parents [...] will 
not give the child the antibiotics because they have thought about it and decided it was not the right thing to do, then they are taking on a high risk [...] and also we have no certainty and freedom when deciding about that child. Because we cannot make decisions about his treatment because we cannot be sure whether [the parent] will carry them out and the child will get better. We have no certainty and then it is hard to cooperate." (I5, 4 PPE)

Facing different types of parents, pediatricians can implicitly or explicitly choose various trust-building strategies, many of which have already been mentioned: giving parents time, avoiding using pressure with vaccinehesitant parents, avoiding "manipulation" through fear, using personal examples and engaging in discussions. We did not have any respondent who said that they were making decisions authoritatively, without taking the parents' opinion into account. The closest that doctors came to such authoritative decisionmaking was when they excluded or screened away refusing parents. However, this can also be interpreted as a decision that aims to actively protect their existing patients, as well as realistically judge their own resources and competences. Another active trust-building strategy used by one of the pediatricians was to show parents that their child is not "just a number" - by mentioning a detail she remembered from their previous visit or talking about the child in a personal manner.

The only participant who received formal training in vaccine-related communication from a pharmaceutical company confirmed that building trust was the prime strategy recommended by communication experts:

"We had a vaccine-manufacturing company here, but she told us correctly, she was a psychologist, that we should not view these [vaccine-refusing] parents as our enemies, but that we should basically praise them for taking good care of their child, to give them the feel- ing that we are on the same boat. That I am also trying to do the best for the child, exactly as she is, that we are not enemies who are against each other but [people] who are together."(I8, $20 \mathrm{PPE})$

If there are any breaches of trust, these are not intentional, as we already mentioned in the Introduction, based on the results of our previous focus-group study with students and mothers (Masaryk, Hatoková, \& Túnyiová, 2015): e.g., not having sufficient space for meaningful discussions, treatment-related decisions viewed by parents as incompetent, or only reporting trivial adverse effects of vaccination. Our respondents had logical and practical explanations for the last issue, and none expressed that they wanted to keep this information a secret, to "manipulate" parents into vaccinating. However, only some actually replaced such inefficient strategy by a more efficient one, e.g. mentioning less common side-effects and what the parent can do about them, or simply admitting that yes, there are some very rare side-effects. As far as lack of time and space for a proper discussion goes, this might partly be a systemic problem, since many Slovak pediatricians have to take on too many patients in order to be economically viable.

\section{Dysfunctional Strategies: "Backfire Effect"}

Another decision-making phenomenon mentioned in the literature was the negative effect of information delivered after a person has made a decision - termed "backfire effect" (Tourangeau \& Rasinski, 1988). Several pediatricians agreed that providing information to parents who have already decided not to vaccinate was not efficient, and rather strengthened their decision rather than persuading them to vaccinate. This was also one of the reasons pediatricians chose to present information to parents early in the decision-making process, making sure that parents encounter sound sci- 
entific information and anchor their decisionmaking to them.

Some doctors understood that with specific types of parents, any information that they would mention after parents have made their decision was not going to change their minds, but spiral into a more and more detailed, but fruitless, discussion.

"That [the child] cannot get it because such diseases do not exist anymore. And that the load is too much for the child's body. When we give him so many antigens in one shot. The argument that the body is ready for an antigen load on the order of billion, billion more antigens than what we give him in this one vaccine, does not work, they do not understand it and they do not want to understand it. Even biochemical explanations do not work. "(I12,4 PPE)

\section{Discussion}

The goal of this exploratory analysis was to identify what communication strategies Slovak pediatricians choose to facilitate parents' vaccination-related decision-making. In general, we were able to confirm that pediatricians have, during their direct experience with mandatory childhood vaccination, developed several "good practices" that largely correspond to the ones highlighted in the scientific literature. Among these, the most universally endorsed one was actively building mutual trust. Pediatricians were aware that trust is the most important factor underlying parents' compliance, and that they had a limited time to create a "solid base" between the first well-child visit and the first scheduled vaccination in the second month. However, even the most efficient trust-building strategies were likely to be significantly limited by institutional barriers, the most obvious one being lack of time for each individual parent due to busy practices.

Other effective strategies were trying to $\mathrm{bal}$ ance risk-benefit communication using acces- sible examples, not resorting to authoritative decision-making, getting the parents to come up with their own decisions based on sound medical information, using charismatic communication such as examples from their own life, and trying to maintain a respectful, non-threatening attitude even when faced with vaccinerefusing parents. Importantly, while our analysis might suggest that pediatricians already use effective communication strategies, this does not entirely capture the reality. First of all, not all of the decisions regarding communication with parents were explicit; there were many instances of strategies that the doctors used implicitly, based on their intuitions developed during years of clinical practice. Secondly, with the exception of one doctor who received training from a pharmaceutical company, all other pediatricians had to devise these strategies by themselves, through trial and error. This was a difficult and often emotionally taxing process, one that they were not prepared for during their medical studies. Also, while as a group, they did report a large number of effective strategies, an individual pediatrician typically had a more limited set; and based on her clinical experience, her individual interpersonal style and the characteristics of her clients, would still struggle with certain aspects of doctor-parent communication. One example was their approach to parents who refused to vaccinate their children. The literature (e.g., Brunson, 2015) suggests that the best approach to vaccinerefusing parents is to keep "communication lines open" and to display a positive, trusting attitude, since parents might change their minds in the long run, e.g. due to external events. At the same time, for a pediatrician, such strategy comes with extra risk in relation to her other patients and places additional strain on her. It is, therefore, logical that some pediatricians from our sample chose to exclude vaccine-refusing parents from their practice. We believe that giving pediatricians efficient tools to be able to 
work with these parents, as well as giving them information that a refusing parent is not "their fault" (Levi, 2007), might be the best course of action in the long run.

All pediatricians reflected on the role offear in parental decisions, which - if too intense expressed itself in non-constructive ways, for instance through parental hostility toward them, or through parents being overly dependent on their decisions. Another recurrent issue was the pediatricians' internal conflict in cases when the parent's and child's interests clashed - such as when parents refused to vaccinate, which some pediatricians viewed as unfair to the child's optimal health. We believe that this difficulty inherent in pediatrician's role is something that needs to be addressed as part of their education. Pediatricians are trained to treat childrenbut this is almost always only possible through cooperation with the children's parents. Therefore, the doctor's "unit of interest" is the parent-child dyad and s/he has to have effective tools to communicate with both, as well as the capacity to make informed choices about which strategy to use in a given situation.

Another interesting topic, especially with regards to the fact that Slovakia has transitioned from an authoritarian to a democratic regime only 25 years ago, was the role of the doctor's authority. In the past, it has been considered entirely normative to have children vaccinated without the parents' consent and often even awareness, such as in classrooms. Also, pediatricians' decisions were generally taken as valid and there was no significant discussion about them. However, this has changed, and shared decision making is now becoming the norm (e.g., Hatoková, 2016).This transition has been difficult for some older pediatricians, who described that they had to learn to deal with their new role. In general, pediatricians informed by their experience are currently choosing to present parents with appropriate information and leave the final decision to them.
One limitation of our study is that since it was based on interviews, we were not able to carry out a more fine-grained analysis based on monitoring pediatricians' actual behavior with the parents (e.g., Opel et al., 2015). For this reason, we also did not focus on particular building blocks, e.g. using jargon vs. accessible language, or eliciting questions, asking for permission to discuss issues, or acknowledging/ listening/emphatizing during discussion (Leask, 2012). These points should be addressed in a follow-up study.

Another possible limitation concerns our sampling procedure. We only recruited pediatricians who were in favor of vaccination. This has its advantages; for example, it reflects the attitude of overwhelming majority of Slovak doctors. There are, however, also possible disadvantages, the most important ones being that vaccination-sceptical pediatricians might be using radically different strategies, or that vaccine-refusing parents might actively seek such pediatricians in greater numbers than typical, accepting pediatricians. Identifying communicative strategies of pediatricians who encourage or actively support refusing parents is a potential area for future studies.

One practical possibility to increase effective decision making about communication tailored to different situations and different personalities of patients' parents, is to train pediatricians in effective communication strategies, not necessarily limited to communication about vaccines. There seems to be a lack of focus on teaching soft skills to future doctors and nurses in Slovakia (Fülöpová \& Gajdošová, 2010), even though it has been shown that satisfactory communication is positively correlated with patients' treatment adherence, and physicians' communication training results in improved patients' adherence (Zolnierek \& Dimatteo, 2009). For those who have received no communication training during their university education, even short-term workshops are a good 
option. Communication training seems to be a good investment, as it leads to increase in patients' trust towards doctors (Street, Makoul, Arora, \& Epstein, 2009). In effect, increasing parents' trust towards their child's doctor would benefit the children, as there would be better cooperation and greater compliance with the prescribed treatment.

\section{Conclusion}

Our analysis is a starting point for implementing a more detailed, evidence-based communication training for pediatricians to help them make explicit, informed decisions about how to effectively facilitate parental decision-making. While our focus is on decisions related to vaccination, improving communication in general will likely result in parents making better decisions about their children health, increase in trust, as well as become less burdensome for doctors.

\section{References}

Benin, A. L., Wisler-Scher, D. J., Colson, E., Shapiro, E. D., \& Holmboe, E. S. (2006). Qualitative analysis of mothers' decision-making about vaccines for infants: The importance of trust. Pediatrics, 117(5), 1532-1541.

Brunson, E. K. (2013). How parents make decisions about their children's vaccinations. Vaccine, 13 , 5466-5470

Brunson, E. K. (2015). Identifying parents who are amenable to pro-vaccination conversations. Global Pediatric Health, 2, 1-7.

Casiday, R. (2005). Risk and trust in vaccine decision making. Durham Anthropology Journal, 13(1), ISSN 1742-2930.

Connolly, T., \& Reb, J. (2012). Toward interactive, Internet-based decision aid for vaccination decisions: Better information alone is not enough. Vaccine, 30(25), 3813-3818.

Edwards, W. (1954). The theory of decision making. Psychological Bulletin, 51(4), 380-417.

Fülöpová, A., \& Gajdošová, M. (2010). Rozvíjanie komunikačných zručností $\mathrm{v}$ zdravotníctve na Slovensku. Verejné zdravotníctvo, VII(4), 1337 1789.
Gust, D. A., Darling, N., Kennedy, A., \& Schwartz, B. (2008). Parents with doubts about vaccines: Which vaccines and reasons why. Pediatrics, 122(4), 718725.

Hastie, R. (2001). Problems for judgment and decision making. Annual Review of Psychology, 52(1), 653683.

Hatoková, M. (2016). Rozhodovanie rodičov o (ne)očkovaní ich detí. In R. Masaryk \& J. Bašnáková (Eds.), Rozhodovanie a usudzovanie VI. Jednotlivec a ostatni: Rozhodovanie v sociálnych kontextoch (pp. 71-99). Olomouc: Univerzita Palackého.

Henrikson, N. B., Opel, D. J., Grothaus, L., Nelson, J., Scrol, A., Dunn, J., ... \& Grossman, D. C. (2015). Physician communication training and parental vaccine hesitancy: A randomized trial. Pediatrics, 136(1), 70-79.

Hertwig, R., \& Hoffrage, U. (2013). Simple heuristics in a social world. Oxford University Press.

http://www.sprievodcaockovanim.sk. (n.d.). Retrieved September 9, 2016.

Jacobson, R. M., Van Etta, L., \& Bahta, L. (2013). The C.A.S.E. approach: Guidance for talking to vaccine-hesitant parents. Minnesota Medicine, 96(4), 49-50.

Kaufman, J., Synnot, A., Ryan, R., Hill, S., Horey, D., Willis, N., ... \& Robinson, P. (2013). Face to face interventions for informing or educating parents about early childhood vaccination. In J. Kaufman (Ed.), The Cochrane database of systematic reviews (Vol. 5, p. CD010038). John Wiley \& Sons, Ltd.

Kennedy, A., Basket, M., \& Sheedy, K. (2011). Vaccine attitudes, concerns, and information sources reported by parents of young children: results from the 2009 HealthStyles survey. Pediatrics, 127 Suppl., S92-S99.

Leask, J., Kinnersley, P., Jackson, C., Cheater, F., Bedford, H., \& Rowles, G. (2012). Communicating with parents about vaccination: A framework for health professionals. BMC Pediatrics, 12(1), 154.

Levi, B. H. (2007). Addressing parents' concerns about childhood immunizations: A tutorial for primary care providers. Pediatrics, 120(1), 18-26.

Lyren, A., \& Leonard, E. (2006). Vaccine refusal: Issues for the primary care physician. Clinical Pediatrics, 45(5), 399-404.

Masaryk, R., Hatoková, M., \& Tunyiová, M. (2015). How students and mothers view child vaccination: Focus group analysis. European Health Psychologist, $S(17), 810$.

Nyhan, B., Reifler, J., Richey, S., \& Freed, G. L. (2014). Effective messages in vaccine promotion: A randomized trial. Pediatrics, 133(4), e835-e842.

Opel, D. J., Heritage, J., Taylor, J. A., Mangione-Smith, R., Salas, H. S., Devere, V., ... \& Robinson, J. D. 
(2013). The architecture of provider-parent vaccine discussions at health supervision visits. Pediatrics, 132(6), 1037-1046.

Opel, D. J., Mangione-Smith, R., Robinson, J. D., Heritage, J., DeVere, V., Salas, H. S., ... \& Taylor, J. A. (2015). The influence of provider communication behaviors on parental vaccine acceptance and visit experience. American Journal of Public Health, 105(10), 1998-2004.

Sadaf, A., Richards, J. L., Glanz, J., Salmon, D. A., \& Omer, S. B. (2013). A systematic review of interventions for reducing parental vaccine refusal and vaccine hesitancy. Vaccine, 31(40), 4293-4304.

Smith, M. (2015). Vaccine safety: Medical contraindications, myths, and risk communication. Pediatrics in Review / American Academy of Pediatrics, 36(6), 227-238.

Smith, P. J., Chu, S. Y., \& Barker, L. E. (2004). Children who have received no vaccines: Who are they and where do they live? Pediatrics, 114(1), 187195.
Smith, P. J., Kennedy, A. M., Wooten, K., Gust, D. A., \& Pickering, L. K. (2006). Association between health care providers' influence on parents who have concerns about vaccine safety and vaccination coverage. Pediatrics, 118(5), e1287-e1292.

Street, R. L., Makoul, G., Arora, N. K., \& Epstein, R. M. (2009). How does communication heal? Pathways linking clinician-patient communication to health outcomes. Patient Education and Counseling, 74(3), 295-301.

Tourangeau, R., \& Rasinski, K. A. (1988). Cognitive processes underlying context effects in attitude measurement. Psychological Bulletin, 103(3), 299-314.

Williams, S. E. (2014). What are the factors that contribute to parental vaccine-hesitancy and what can we do about it? Human Vaccines and Immunotherapeutics, 10(9), 2584-2596.

Zolnierek, K. B. H., \& Dimatteo, M. R. (2009). Physician communication and patient adherence to treatment: A meta-analysis. Medical Care, 47(8), 826834 . 